\title{
The role of tectonic uplift, climate, and vegetation in the long-term terrestrial phosphorous cycle
}

\author{
C. Buendía ${ }^{1}$, A. Kleidon ${ }^{1}$, and A. Porporato ${ }^{2}$ \\ ${ }^{1}$ Max Planck Institut für Biogeochemie, P.O. Box 1001 64, Jena, 07701, Germany \\ ${ }^{2}$ Department of Civil Environmental Engineering, Duke University, Durham, NC 27708, USA
}

Received: 23 December 2009 - Published in Biogeosciences Discuss.: 14 January 2010

Revised: 11 June 2010 - Accepted: 14 June 2010 - Published: 25 June 2010

\begin{abstract}
Phosphorus (P) is a crucial element for life and therefore for maintaining ecosystem productivity. Its local availability to the terrestrial biosphere results from the interaction between climate, tectonic uplift, atmospheric transport, and biotic cycling. Here we present a mathematical model that describes the terrestrial P-cycle in a simple but comprehensive way. The resulting dynamical system can be solved analytically for steady-state conditions, allowing us to test the sensitivity of the P-availability to the key parameters and processes. Given constant inputs, we find that humid ecosystems exhibit lower P availability due to higher runoff and losses, and that tectonic uplift is a fundamental constraint. In particular, we find that in humid ecosystems the biotic cycling seem essential to maintain long-term Pavailability. The time-dependent $\mathrm{P}$ dynamics for the Franz Josef and Hawaii chronosequences show how tectonic uplift is an important constraint on ecosystem productivity, while hydroclimatic conditions control the P-losses and speed towards steady-state. The model also helps describe how, with limited uplift and atmospheric input, as in the case of the Amazon Basin, ecosystems must rely on mechanisms that enhance P-availability and retention. Our novel model has a limited number of parameters and can be easily integrated into global climate models to provide a representation of the response of the terrestrial biosphere to global change.
\end{abstract}

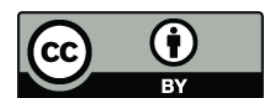

Correspondence to: C. Buendía (cbuendia@bgc-jena.mpg.de)

\section{Motivation}

Phosphorus (P) is a particularly important element for life. At small-scales, it serves as the driver of cellular energy cycles and is also responsible for building the molecules DNA and RNA. At larger scales, ecosystem productivity is often constrained by the availability of P (Chadwick et al., 1999; Walker and Syers, 1976; Wardle, 2004; Wardle et al., 2009; Crews et al., 1995). In contrast to other macronutrients (e.g., nitrogen), once released from its geologic source, $\mathrm{P}$ is quickly converted into less available forms or is removed from the land system by erosion and run-off (Walker and Syers, 1976). In the context of abiotically controlled processes, the P-cycle is closed on geologic time scales (ca. 1 million years) by uplift of fresh material to the soil. Therefore, alterations to the P-cycle could have long-lasting consequences (Sanchez et al., 1982). Embedded within this slow cycle, $\mathrm{P}$ is cycled relatively quickly between the soil and vegetation (Wood et al., 1984; Jordan and Herrera, 1981; Vitousek and Sanford, 1986). This delicate balance of the P-cycle is well known within the agricultural and environmental engineering context: an insufficient $\mathrm{P}$ supply causes vegetation stress, while excessive fertilization quickly contributes to groundwater and streamflow contamination (Sanchez et al., 1982; Brady and Weil, 2008).

Soil formation and how this influences $\mathrm{P}$ availability is studied using data obtained from chronosequences. A chronosequence is a sequence of soils, developed on similar parent materials and relief, under the influence of constant or ineffectively varying climate and biotic factors, whose differences can thus be ascribed to the time lapsed since the

Published by Copernicus Publications on behalf of the European Geosciences Union. 
initiation of the soil formation (Stevens and Walker, 1970). Chronosequences start after catastrophic phenomena such as volcanic activity, floods, or glaciation (Stevens and Walker, 1970), which restart soil formation. Thus, in these cases, the age of the soil is approximately known, and the use of chronosequence data is useful to understand the transient dynamics of the P-cycle. Based on chronosequence data Walker and Syers (1976) proposed a conceptual scheme to explain the depletion of terrestrial phosphorus. This classical study explains how $\mathrm{P}$, as primary material, gets depleted with soil age transformed into less available forms or leached away. Their study also outlines the importance of exogenous P inputs to support the productivity of ecosystems at later stages in soil evolution.

Most of the terrestrial productivity, however, occurs in soils that refresh continuously, due to the action of tectonic and isostatic uplift and in the presence of exogenous $\mathrm{P}$ inputs. To shed light on the role of isostatic uplift, Porder et al. (2007) developed a model that accounts for uplift by assuming a steady-state in which uplift equals erosion. Their model study suggested that for areas with moderate uplift rates, $\mathrm{P}$ depletion is unlikely, whereas in areas with slow uplift rates, like the Amazon Basin, ecosystems will depend more strongly on atmospheric inputs (Porder et al., 2007). Along similar lines, but from the data perspective, a study by Jordan (1982), assuming steady state conditions for the Amazon ecosystem, showed that the P atmospheric deposition was highly correlated with the $\mathrm{P}$ riverine output of the system. This suggested that the soils are not a source of $\mathrm{P}$ for the lowland Amazon Basin and that, instead, Saharan dust deposition is contributing to its P input (Jordan, 1982). Later, Swap et al. (1992) demonstrated that the total amount of atmospheric deposition was actually composed mainly of biogenic particles originated locally from internal recycling of the natural system and from local fires, even showing a net loss to the atmosphere of $1.3 \mathrm{mg} \mathrm{P} \mathrm{m}^{-2} \mathrm{a}^{-1}$ for the whole Amazon Basin (Swap et al., 1992; Mahowald et al., 2005). These findings point at a need of re-evaluating the possible role of all inputs and losses on the long-term ecosystem behavior. For example, in reference to the Hawaiian Islands, it was shown that the dust particles coming from Continental Asia contributed to the productivity, once the $\mathrm{P}$ in fresh volcanic rock was depleted (Chadwick et al., 1999; Kurtz et al., 2001). Moreover, Wardle et al. (2009) showed that seabird colonies, with guano deposition are important P-sources in some ecosystems.

On the one hand, given the inherent difficulty in monitoring soil biogeochemical cycles at a sufficiently precise spatial and temporal resolution, numerical models have been commonly used to analyze the role of different processes in maintaining stable $\mathrm{P}$ cycling and thus ecosystem productivity, as well as to understand to what extent terrestrial productivity may feed back on the $\mathrm{CO}_{2}$ concentration and climate change (Cramer et al., 2001). Some of these studies have been criticized for overestimating both, future terrestrial carbon sequestration and the potential carbon climate feedback, because they do not account for nutrient constraints (Hungate et al., 2003). There are now models that account for the $\mathrm{N}$ constraint (e.g., Zaehle et al., 2010), and even for the relationships between P, C and N (e.g., Parton et al., 1988; Wang et al., 2007), but still do not consider longer timescale processes such as uplift.

On the other hand, extracting the dominant processes responsible for the long-term biogeochemical interactions may be difficult in these complex models, which typically involve an extremely large number of parameters and degrees of freedom, and where the results are necessarily numerical. In this regard, simplified analytical models provide a useful alternative, especially when cast in the form of systems of ordinary differential equations (Manzoni et al., 2004; Lasaga, 1980; DeLonge et al., 2008), for which the apparatus of dynamical system theory becomes readily available (e.g., Strogatz, 1994). With this intent, here we propose a simple analytical P-cycle model, valid at long temporal (decades and higher) and large spatial (regional to continental) scales, with the aim of clarifying how tectonic uplift, climate, vegetation, and exogenous inputs interact to maintain the active P-cycle in terrestrial ecosystems under different hydroclimatic conditions. Given its simplicity, the model can be easily coupled to other models of biogeochemical cycles, be used to initialize the phosphorus pools of more complex models running on daily or sub-daily time-scales, or simply be analyzed and modified to generate research hypotheses.

In the following, we describe the P-cycle model. We then calculate the steady-state for ecosystems without uplift (e.g., Franz Joseph and volcanic islands such as Hawaii), as well as for ecosystems with constant uplift (e.g., tectonic uplift and isostatic rebound as in the Amazon Basin). Using the steadystate solutions, we evaluate how $\mathrm{P}$ availability in terrestrial ecosystems is affected by (a) reduction of organic biomass losses, (b) active P uptake by vegetation and (c) the input of $\mathrm{P}$ by animals. Finally, the implications of these processes are discussed in the context of Hawaii, New Zealand and the Amazon Basin using a time-dependent solution of our model.

\section{Model formulation}

We formulate our model based on the schematic P-cycle representation of Fig. 1. Symbols and units are summarized in Table 1, with Table 2 providing an explanation of the parameters. Possible ranges of the inputs, fluxes, and pools are included in Fig. 1. Our model considers the average vertical content of $\mathrm{P}$ throughout the soil layer.

\subsection{Synthesis of the P-cycle model}

Phosphorus has a very slow geochemical cycle driven mainly by tectonic processes. The uplift of primary material $\left(I_{\mathrm{W}}\right)$ is the primary input to the land system. Weathering $\left(F_{\mathrm{wd}}\right)$ is the 


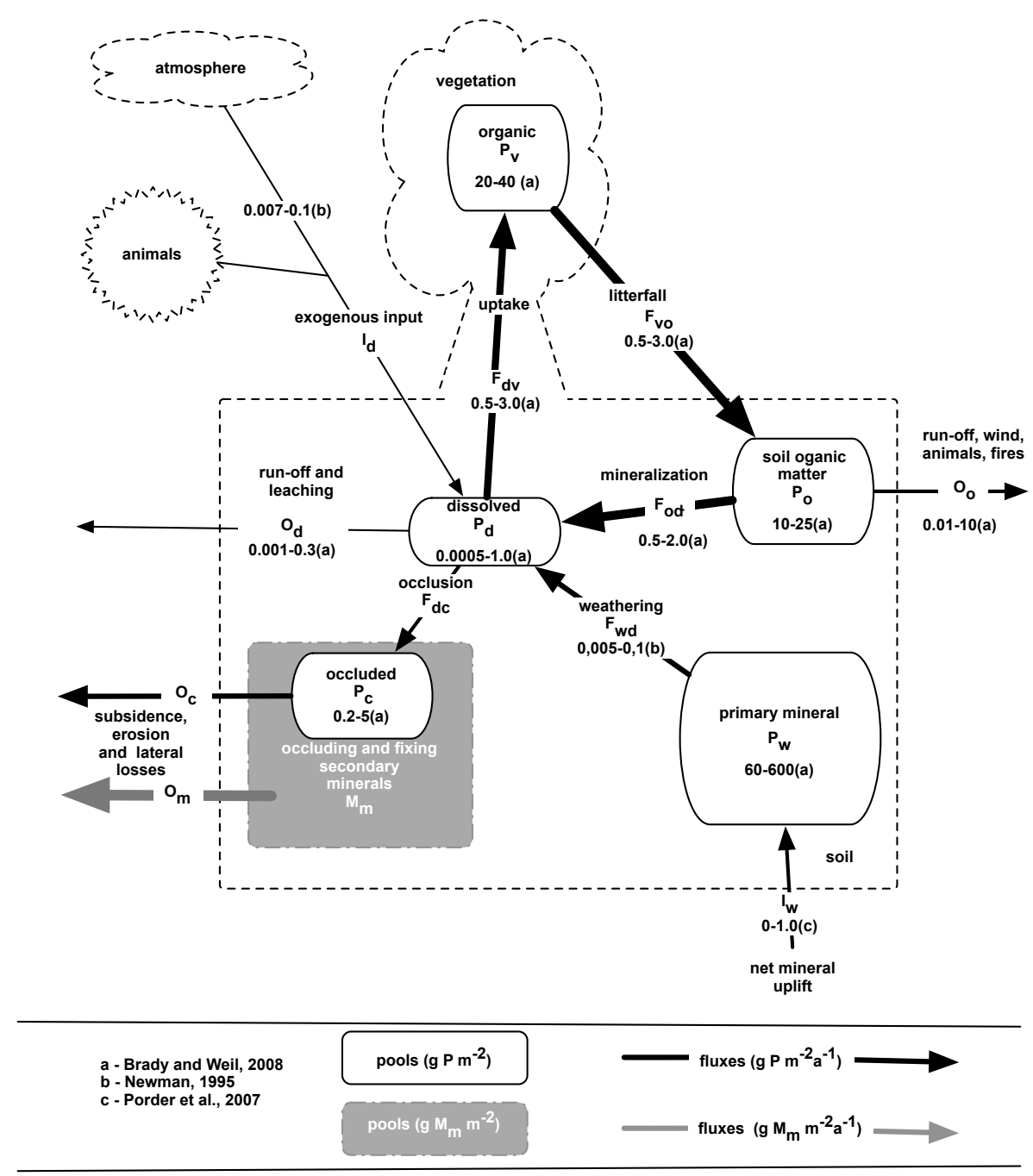

Fig. 1. Schematic representation of the terrestrial phosphorus cycle as described mathematically using Eqs. (12-17). Sizes of the fluxes and pools are taken from the literature (Brady and Weil, 2008; Porder et al., 2007; Newman, 1995). The thickness of the arrows relates to the size of the fluxes.

next step where primary mineral phosphorus $\left(P_{\mathrm{w}}\right)$, normally in the form of apatite, is transformed into a dissolved phosphate form $\left(P_{\mathrm{d}}\right)$. Within this phase, aluminum, manganese, and iron are released from primary mineral sources during weathering $\left(F_{\mathrm{wm}}\right)$. These ions stay in the soil to form secondary minerals or clays $\left(M_{\mathrm{m}}\right)$. These secondary minerals can absorb phosphate in soil solution $\left(P_{\mathrm{d}}\right)$ to form bonded $\mathrm{P}$ compounds $\left(P_{\mathrm{c}}\right)$ that are almost insoluble, acting as a sink of $\mathrm{P}$ in the system. As weathering takes place, secondary minerals form, resulting in old soils having a greater P-retention capacity (Olander and Vitousek, 2005). P in soil solution is taken up by vegetation $\left(F_{\mathrm{pv}}\right)$, either passively with root water uptake, or actively by osmotic adjustments in roots and by mycorrhizal uptake (Jordan and Herrera, 1981). In plants, with the synthesis of organic matter, $P$ becomes part of vegetation biomass $\left(P_{\mathrm{v}}\right)$. Litterfall then releases $\mathrm{P}$ back into the soil $\left(F_{\mathrm{vo}}\right)$, as soil organic matter $\left(P_{\mathrm{o}}\right)$, in forms bound to carbon and nitrogen. After mineralization $\left(F_{\text {od }}\right), \mathrm{P}$ again becomes available to vegetation.

\subsection{Climatic forcing}

We investigate different climate regimes represented by differences in mean soil moisture and temperature. Soil moisture content drives the dynamics of several biogeochemical fluxes, including mineralization, leaching, and plant uptake (Porporato et al., 2003). The long-term relative soil moisture content, $s$, is defined as the volumetric soil moisture divided by soil porosity. This dimensionless parameter is assumed to have average values between 0.1 and 0.8 . In fact, $s$ rarely goes below plant wilting point, which is on the order of 0.1 , and above field capacity, typically around 0.6-0.8 (Rodriguez-Iturbe and Porporato, 2004). Soil water content 
Table 1. Description of symbols.

\begin{tabular}{clll}
\hline & Symbol & Description & Units \\
\hline pools & $P_{\mathrm{W}}$ & phosphorus in primary material in the soil & $\mathrm{g} \mathrm{P} \mathrm{m}^{-2}$ \\
& $M_{\mathrm{m}}$ & secondary minerals & $\mathrm{g} \mathrm{M} \mathrm{m}^{-2}$ \\
& $P_{\mathrm{c}}$ & phosphorus occluded in secondary minerals & $\mathrm{g} \mathrm{P} \mathrm{m}^{-2}$ \\
& $P_{\mathrm{V}}$ & phosphorus in vegetation & $\mathrm{g} \mathrm{P} \mathrm{m}^{-2}$ \\
& $P_{\mathrm{O}}$ & phosphorus in soil biomass & $\mathrm{g} \mathrm{P} \mathrm{m}^{-2}$ \\
& $P_{\mathrm{d}}$ & phosphorus in soil solution & $\mathrm{g} \mathrm{P} \mathrm{m}^{-2}$ \\
\hline \multirow{2}{*}{ fluxes } & $F_{\mathrm{Wd}}$ & phosphorus weathering & $\mathrm{g} \mathrm{P} \mathrm{m}^{-2} \mathrm{a}^{-1}$ \\
& $F_{\mathrm{wm}}$ & secondary mineral formation & $\mathrm{g} \mathrm{P} \mathrm{m}^{-2} \mathrm{a}^{-1}$ \\
& $F_{\mathrm{dc}}$ & phosphorus occlusion & $\mathrm{g} \mathrm{P} \mathrm{m}^{-2} \mathrm{a}^{-1}$ \\
& $F_{\mathrm{dv}}$ & phosphorus uptake by vegetation & $\mathrm{g} \mathrm{P} \mathrm{m}^{-2} \mathrm{a}^{-1}$ \\
& $F_{\mathrm{Vo}}$ & phosphorus losses from vegetation & $\mathrm{g} \mathrm{P} \mathrm{m}^{-2} \mathrm{a}^{-1}$ \\
& $F_{\mathrm{od}}$ & phosphorus mineralization & $\mathrm{g} \mathrm{P} \mathrm{m}^{-2} \mathrm{a}^{-1}$ \\
\hline \multirow{2}{*}{ losses } & $O_{\mathrm{m}}$ & secondary minerals & $\mathrm{g} \mathrm{P} \mathrm{m}^{-2} \mathrm{a}^{-1}$ \\
& $O_{\mathrm{O}}$ & phosphorus in organic form & $\mathrm{g} \mathrm{P} \mathrm{m}^{-2} \mathrm{a}^{-1}$ \\
& $O_{\mathrm{c}}$ & phosphorus in occluded form & $\mathrm{g} \mathrm{P} \mathrm{m}^{-2} \mathrm{a}^{-1}$ \\
& $O_{\mathrm{d}}$ & phosphorus in soil solution & $\mathrm{g} \mathrm{P} \mathrm{m}^{-2} \mathrm{a}^{-1}$ \\
\hline inputs & $I_{\mathrm{d}}$ & phosphorus in dissolvable form & $\mathrm{g} \mathrm{P} \mathrm{m}^{-2} \mathrm{a}^{-1}$ \\
& & transported by atmosphere and animals & \\
& $I_{\mathrm{W}}$ & phosphorus supplied by uplift & $\mathrm{g} \mathrm{P} \mathrm{m}^{-2} \mathrm{a}^{-1}$ \\
\hline
\end{tabular}

per unit ground area over a rooting depth of $Z_{\mathrm{r}}$ is given by $n Z_{\mathrm{r}} s$, where $n$ is soil porosity (in our simulations we used a mean soil porosity of 0.4 ).

\subsection{Inputs}

\subsubsection{Atmospheric transport and input from animals}

The atmosphere can transport phosphorus in the form of small particles (ashes, soil dust or biogenic) for thousands of kilometers, thereby affecting the local P budget (Artaxo and Hansson, 1994). This input can annually range from 0.0007 to $0.1 \mathrm{~g} \mathrm{P} \mathrm{m}^{-2}$ (Newman, 1995). At the local scale, animals may also be an important $P$ source accounting not only for the redistribution of nutrients on land, but also returning $\mathrm{P}$ from the ocean or fresh water ecosystem to land (Wardle et al., 2009). Vegetation has also been shown to increase depositional inputs from the atmosphere (Lawrence et al., 2007). Although it is difficult to estimate these inputs, it is important to include them in the model even in an approximate way to explore their potential importance. We refer to the sum of those two inputs, animal from ocean or fresh water ecosystems to land and what is carried by the atmospheric transport, as dissolvable input $I_{\mathrm{d}}$. For simplicity we assume that those $\mathrm{P}$ inputs enter directly into the dissolved pool, as the nature of the inputs is quite different and therefore it is difficult to estimate when they become really available. We also refer to $I_{\mathrm{d}}$ as the exogenous input, to remember that we only consider the external inputs. It should be noted that this input does not account for the terrestrial redistribution of $\mathrm{P}$ due to animals but only for external inputs.

\subsubsection{Input by tectonic and isostatic uplift}

The uplift of metamorphic, sedimentary, and igneous rocks to the land surface marks the beginning of the phosphorus cycle. The amount of $\mathrm{P}$ in the fresh rock entering the soil profile driven by tectonic and isostatic uplift is expressed in the model as $I_{\mathrm{w}}$. In steady state, it is assumed that uplift equals erosion. We use this parameter to compare different tectonic configurations, as suggested by Porder et al. (2007), who accounted for this input by considering the local uplift rates and $\mathrm{P}$ concentration in primary mineral. Typically, uplift can range from 0 to approximately $8 \mathrm{~m}$ per thousand years (Porder et al., 2007).

\subsection{Ecosystem internal fluxes}

\subsubsection{Phosphorus weathering}

Once the P-containing rock enters the root zone, it is more easily chemically and physically weathered $\left(F_{\mathrm{wd}}\right)$. Since weathering of one mole of apatite requires four mols of $\mathrm{CO}_{2}$ and three moles of $\mathrm{H}_{2} \mathrm{O}$, and $\mathrm{CO}_{2}$ is normally found in nonlimiting concentrations, it is reasonable to assume that in the reaction, water and apatite concentrations are the limiting components (Chameides and Perdue, 1997). For simplicity, we will not account explicitly for the effect of temperature and temperature changes in our weathering reaction. Weathering is thus modeled as

$F_{\mathrm{wd}}=k_{\mathrm{w}} f_{\mathrm{w}}(s) P_{\mathrm{w}}$,

where $f_{\mathrm{w}}(s)$ is a function of soil moisture and $k_{\mathrm{w}}$ is a reaction at a constant rate which depends on the annual temperature gradient and hardness of the weatherable material.

\subsubsection{Formation of secondary minerals and $P$ occlusion}

During soil development, $\mathrm{Al}, \mathrm{Mn}, \mathrm{Fe}$, and $\mathrm{P}$ compounds found in the rocks are released into the soil by weathering. $\mathrm{Al}, \mathrm{Fe}$, and $\mathrm{Mn}$ differ from $\mathrm{P}$ in that they tend to form secondary minerals. The occlusion of $\mathrm{P}$ by clays containing $\mathrm{Al}, \mathrm{Fe}$, and $\mathrm{Mn}$ is considered to be an important sink of $\mathrm{P}$ and therefore, although our model strives to be simple, we introduce a pool of secondary minerals $M_{\mathrm{m}}$, to account for the phosphorus retention capacity of the soil, which increases with soil-substrate age (Olander and Vitousek, 2005). This pool represents an important difference to the model of Porder et al. (2007).

To derive the rate of weathering and later formation of this secondary mineral, we simply assume it to be proportional to phosphorus weathering

$F_{\mathrm{wm}}=k_{\mathrm{m}} F_{\mathrm{wd}}$,

where $k_{\mathrm{m}}$ takes into account that different parent material types may have different element concentrations and result in different types and amounts of clays. Occlusion or fixation 
Table 2. Description of model parameters.

\begin{tabular}{|c|c|c|c|c|}
\hline Parameter & Description & Value & Units & Reference \\
\hline$s$ & yearly averaged soil moisture & $0.1-0.8$ & dimensionless & Porporato et al. (2003) \\
\hline$\eta$ & maximum transpiration rate & 5 & $\mathrm{~mm} \mathrm{~m}^{-2}$ day $^{-1}$ & Porporato et al. (2003) \\
\hline$Z_{\mathrm{r}}$ & effective soil depth & 1 & $\mathrm{~m}$ & chosen value \\
\hline$n$ & porosity & 0.4 & dimensionless & chosen value \\
\hline$k_{\mathrm{W}}$ & weathering rate & 0.0001 & $\mathrm{a}^{-1}$ & constrained by Franz Josef and Hawaii rates (Table 3) \\
\hline$k_{\mathrm{m}}$ & secondary mineral formation rate & 0.7 & $a^{-1}$ & chosen value \\
\hline$k_{\mathrm{c}}$ & phosphorus occlusion rate & 0.00005 & $\mathrm{~m}^{2} \mathrm{a}^{-1} \mathrm{~g}^{-1}$ & chosen value \\
\hline$k_{\mathrm{e}}$ & ice, wind and gravitational driven losses & 0.00001 & $a^{-1}$ & chosen value \\
\hline$k_{1}$ & runoff/leakage rate at saturation & 0.1 & $\mathrm{a}^{-1}$ & Porporato et al. (2003) \\
\hline$k_{\mathrm{d}}$ & mineralization rate & 0.18615 & $a^{-1}$ & chosen value \\
\hline$k_{\mathrm{V}}$ & litter fall rate & 0.20075 & $a^{-1}$ & chosen value \\
\hline$k_{\mathrm{r}}$ & losses regulation rate & 0.002 & $\mathrm{a}^{-1}$ & see steady-state solution \\
\hline$k_{\mathrm{u}}$ & active uptake by vegetation & 10 & dimensionless & see steady-state solution \\
\hline$k_{\mathrm{f}}$ & ice, wind, human, fire losses rate & 0.0005 & $a^{-1}$ & see steady-state solution \\
\hline
\end{tabular}

of phosphorus in $M_{\mathrm{m}}\left(F_{\mathrm{dc}}\right)$ is proportional to the amount of $\mathrm{P}$ in dissolved form $\left(P_{\mathrm{d}}\right)$ and the amount of $M_{\mathrm{m}}$, that is

$F_{\mathrm{dc}}=k_{\mathrm{c}} P_{\mathrm{d}} M_{\mathrm{m}}$,

where $k_{\mathrm{c}}$ is a parameter that can be adjusted to obtain realistic occlusion rates. While some soils can occlude as much as $240 \mathrm{~g} \mathrm{P} \mathrm{m}^{-2}$, soils with occlusion of $70 \mathrm{~g} \mathrm{P} \mathrm{m}^{-2}$ are still considered high P-occluding soils (Brady and Weil, 2008).

\subsubsection{Vegetation P-uptake and litter fall}

Since actual evapotranspiration is highly correlated to net annual productivity (Rosenzweig, 1968), we assume that the $\mathrm{P}$ uptake by vegetation will be mainly driven by root water uptake. In steady state the transpiration rate $T(s)$ equals root water uptake (Porporato et al., 2003). Transpiration is assumed to be linearly related to relative soil moisture. The linearity assumption may be justified by the role of heterogeneity at the large space-time scales of interest here (e.g., Porporato et al., 2004; Katul et al., 2007). Vegetation Puptake is defined as

$F_{\mathrm{dv}}=k_{\mathrm{u}} T(s) \frac{P_{\mathrm{d}}}{n Z_{\mathrm{r}} s}$

where $T(s)=s \eta$ (assuming a maximum transpiration rate $\left.\eta=5 \mathrm{~mm} \mathrm{~d}^{-1}\right), k_{\mathrm{u}}$ is a spatially-averaged parameter accounting for the role of diffusion and mycorrhizae hyphae in the movement of the phosphate ions to plant roots (Jordan and Herrera, 1981; Herrera et al., 1981), and $\frac{P_{\mathrm{d}}}{n Z_{\mathrm{r}} s}$ is the $\mathrm{P}$ concentration in soil solution. Across terrestrial ecosystems, the carbon to phosphorus molar ratio ranges in foliage from 900 in temperate regions to 2450 in tropical regions, with typical litterfall molar ratios from about 1700 in temperate regions to 4100 in tropical regions (McGroddy et al., 2004; Manzoni et al., 2010). We therefore do not assume a constant $\mathrm{C}$ to $\mathrm{P}$ ratio in plants. The amount of $\mathrm{P}$ lost from vegetation by litterfall $\left(F_{\mathrm{vo}}\right)$ is described as a fractional loss per year $\left(k_{\mathrm{p}}\right)$ of total $\mathrm{P}$ in the vegetation

$F_{\mathrm{vo}}=k_{\mathrm{p}} P_{\mathrm{v}}$

\subsubsection{P-mineralization}

Phosphorus mineralization $\left(F_{\mathrm{od}}\right)$ is the transformation of organic $\mathrm{P}$ in soil organic matter $\left(P_{\mathrm{o}}\right)$ to mineral phosphorus, $P_{\mathrm{d}}$. Organic matter decomposition is a process driven by soil microbes, whose rate of activity in turn depends on soil moisture $(s)$ and temperature $(T)$ (Porporato et al., 2003). Assuming first order kinetics, we express mineralization as

$F_{\mathrm{od}}=k_{\mathrm{d}} f(s, T) P_{\mathrm{o}}$

where decomposition increases with soil moisture, temperature and high $\mathrm{P}$ content. Although nitrogen in some ecosystems may also play an important role (Manzoni et al., 2010), for simplicity it will be left out.

\subsection{Losses}

Phosphorus is lost from the system by surface runoff, drainage, erosion, fire, and anthropogenic removal. Drainage and runoff $(L Q(s))$ is a nonlinear function of soil moisture (e.g., Rodriguez-Iturbe and Porporato, 2004) represented by

$L Q(s)=k_{1} s^{c}$

where $k_{1}$ accounts for the runoff-leakage rate at saturation. Losses from the dissolved inorganic $\mathrm{P}$ pool $\left(O_{\mathrm{d}}\right)$ are mainly driven by runoff and deep infiltration, $L Q(s)$, and are proportional to the total concentration of $P_{\mathrm{d}}$

$O_{\mathrm{d}}=L Q(s) \frac{P_{\mathrm{d}}}{n Z_{\mathrm{r}} s}$. 
Losses of organic matter from the system are in part assumed to be linked to water losses, but a separate term, $k_{\mathrm{f}}$, is used to account for the losses by natural processes (e.g., glaciation and wind erosion), and induced losses as a result of human activity (e.g., fires and biomass removal) (Manzoni et al., 2010; Mahowald et al., 2005; Porder and Chadwick, 2009). As a result, the external P-losses from the soil organic matter pool are

$O_{\mathrm{o}}=\left(k_{\mathrm{r}} L Q(s)+k_{\mathrm{f}}\right) P_{\mathrm{o}}$.

We also account for erosion, subsidence, and lateral losses of secondary minerals $\left(O_{\mathrm{m}}\right)$ and occluded $\mathrm{P}\left(O_{\mathrm{c}}\right)$. For simplicity, these are described using a constant rate $k_{\mathrm{e}}$

$O_{\mathrm{m}}=k_{\mathrm{e}} M_{\mathrm{m}}$

and

$O_{\mathrm{c}}=k_{\mathrm{e}} P_{\mathrm{c}}$

\subsection{P-balance equations}

Based on the previous assumptions, the following ordinary differential equations describe the dynamics of the five $\mathrm{P}$ pools, plus the secondary mineral pool (Fig. 1). The primary mineral $\mathrm{P}$ in the soil profile $\left(P_{\mathrm{w}}\right)$ increases with the uplift process $\left(I_{\mathrm{W}}\right)$ and decreases as weathering reactions take place $F_{\text {wd }}$ (described in Eq. 1),

$\frac{d P_{\mathrm{w}}}{d t}=I_{\mathrm{w}}-F_{\mathrm{wd}}$.

The amount of secondary minerals increases by weathering $F_{\text {wm }}$ (Eq. 2) and decreases by erosion, subsidence, and lateral losses $O_{\mathrm{m}}$ (Eq. 10)

$\frac{d M_{\mathrm{m}}}{d t}=F_{\mathrm{wm}}-O_{\mathrm{m}}$

We describe the dynamics of the occluded $\mathrm{P}$ pool $\left(P_{\mathrm{c}}\right)$ by accounting for occlusion $\left(F_{\mathrm{dc}}\right)$, a non-linear term that depends on the size of the secondary mineral pool and the amount of $P$ in soil solution (Eq. 3). Since de-occlusion of P only seems to play an important role on shorter time scales (Richter et al., 2006), we account only for losses related to erosion processes $O_{\mathrm{c}}$ (refer to Eq. 11)

$\frac{d P_{\mathrm{c}}}{d t}=F_{\mathrm{dc}}-O_{\mathrm{c}}$.

The dynamics of the $\mathrm{P}$ pool in vegetation $\left(P_{\mathrm{v}}\right)$ is determined by the balance between $\mathrm{P}$ uptake $F_{\mathrm{dv}}$ (Eq. 4 ) and litterfall $\left(F_{\mathrm{vo}}\right)($ Eq. 5)

$\frac{d P_{\mathrm{v}}}{d t}=F_{\mathrm{dv}}-F_{\mathrm{vo}}$.

We describe the dynamics of $\mathrm{P}$ in the soil organic matter as the balance between the input from vegetation litter $F_{\mathrm{vo}}$
(Eq. 5), the losses from mineralization $F_{\text {od }}$ (Eq. 6), and losses due to fire, erosion, and water runoff $F_{\text {ov }}$ (Eq. 9)

$\frac{d P_{\mathrm{o}}}{d t}=F_{\mathrm{vo}}-F_{\mathrm{od}}-O_{\mathrm{o}}$

The $\mathrm{P}$ in soil solution $\left(P_{\mathrm{d}}\right)$ bridges the decomposition, weathering, external losses, and occlusion. The three inputs to this pool are exogenous inputs $I_{\mathrm{d}}$, mineralization $F_{\text {od }}$ (Eq. 6), and weathering $F_{\mathrm{wd}}$ (Eq. 1). Vegetation uptake $F_{\mathrm{dv}}$ (Eq. 4), occlusion in secondary minerals $F_{\mathrm{dc}}$ (Eq. 3), and the runoff and leakage $O_{\mathrm{d}}$ (Eq. 8) account for the P losses

$\frac{d P_{\mathrm{d}}}{d t}=I_{\mathrm{d}}+F_{\mathrm{wd}}+F_{\mathrm{od}}-\left(F_{\mathrm{dv}}+F_{\mathrm{dc}}+O_{\mathrm{d}}\right)$

where $F_{\mathrm{dc}}$ is a non-linear term (Eq. 3).

\section{Results}

We evaluate the role of tectonic uplift and the implication of the ecological processes in the context of the P-cycle across different climates. Because of the model simplicity and few nonlinearities, it is actually possible to analytically obtain the general steady-steady solution of the system. We are then able to perform a sensitivity analysis of the main parameters, as well as, an analysis of the relative roles of the inputs and climate forcing.

\subsection{Steady-state solution}

The steady-state solutions are obtained by setting the time derivatives of the phosphorus cycle (Eqs. 12-17) to zero. The corresponding solutions, indicated with a hat, are obtained in closed form as Eqs. (18-23)

$$
\begin{aligned}
& \hat{P}_{\mathrm{w}}=\frac{I_{\mathrm{w}}}{k_{\mathrm{w}} \cdot f_{\mathrm{w}}(s)} \\
& \hat{M}_{\mathrm{m}}=\frac{k_{\mathrm{m}} I_{\mathrm{w}}}{k_{\mathrm{e}}} \\
& \hat{P}_{\mathrm{c}}=\frac{k_{\mathrm{c}} \hat{P}_{\mathrm{d}} \hat{M}_{\mathrm{m}}}{k_{\mathrm{e}}^{2}} \\
& \hat{P}_{\mathrm{o}}=\frac{k_{\mathrm{v}} \hat{P}_{\mathrm{v}}}{k_{\mathrm{d}} f(s, T)+k_{\mathrm{f}}+k_{\mathrm{r}} L Q(s)} \\
& \hat{P}_{\mathrm{v}}=\frac{T(s) \hat{P}_{\mathrm{d}}}{k_{\mathrm{v}} n Z_{\mathrm{r}} s}
\end{aligned}
$$

$$
\hat{P}_{\mathrm{d}}=\frac{\left(I_{\mathrm{d}}+I_{\mathrm{w}}\right) k_{\mathrm{e}} n Z_{\mathrm{r}} s\left(k_{\mathrm{d}} f(s, T)+k_{\mathrm{r}} L Q(s)+k_{\mathrm{f}}\right)}{k_{\mathrm{f}} f(s, T)\left(k_{\mathrm{c}} L Q(s)+k_{\mathrm{c}} k_{\mathrm{m}} I_{\mathrm{w}} n Z_{\mathrm{r}} s\right)+\left(k_{\mathrm{f}}+k_{\mathrm{r}} L Q(s)\right)\left(k_{\mathrm{c}} k_{\mathrm{m}} I_{\mathrm{w}} Z_{\mathrm{r}} s+k_{\mathrm{e}} L Q(s)+T(s)\right)}
$$

We then analyze the solution as a function of soil moisture $(s)$, uplift $\left(I_{\mathrm{W}}\right)$, and exogenous inputs $\left(I_{\mathrm{d}}\right)$. 

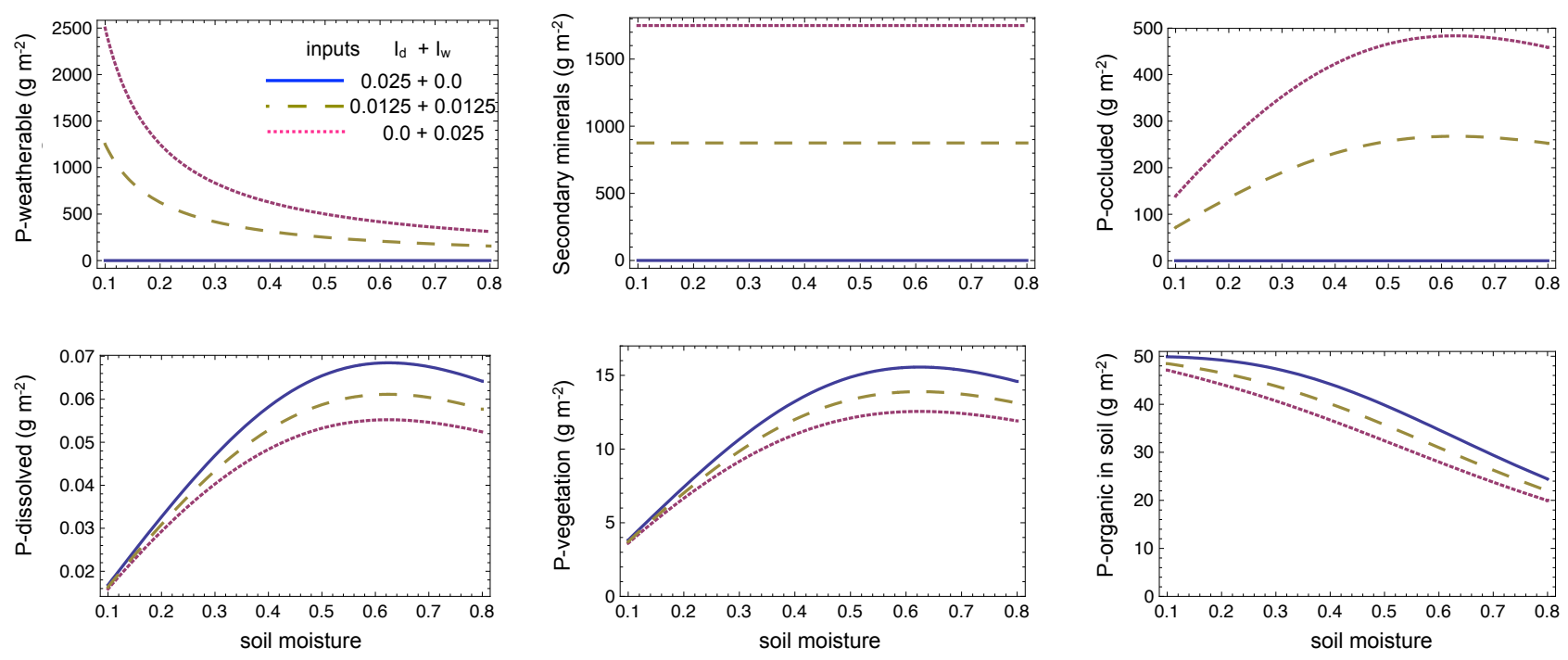

Fig. 2. Sensitivity of $\mathrm{P}$ external input to soil moisture. The dotted lines represent ecosystems depending only on uplift ( $\left.I_{\mathrm{W}}\right)$, the solid lines represent ecosystem depending only on exogenous input $\left(I_{\mathrm{d}}\right)$ and the dashed lines represent ecosystems depending on both, $I_{\mathrm{W}}$ and $I_{\mathrm{d}}$. For these simulations we used the steady-state solution, presented in Eqs. (18)-(23). Refer to Table 2 for the parameters used.

\subsubsection{Sensitivity of ecosystems external inputs to soil moisture}

Changes in the rainfall regime alter soil moisture, which in turn affects weathering, runoff, vegetation water uptake, and mineralization of organic matter. Figure 2 shows the steady-state of ecosystems under different soil moisture conditions, from very dry $(s=0.1)$ to very wet $(s=0.8)$. The effects of soil moisture changes are analyzed for the three different forms of input, keeping the total input constant $\left(I_{\mathrm{d}}+I_{\mathrm{w}}=0.025 \mathrm{~g} \mathrm{P} \mathrm{m}^{-2} \mathrm{a}^{-1}\right)$.

By comparing the three different types of inputs in Fig. 2, we observe differences in the amount of $\mathrm{P}$ in primary minerals (P-weatherable), the $\mathrm{P}$ retention capacity (secondary minerals), and the $\mathrm{P}$ in occluded form. Occlusion does not have a large influence on the $\mathrm{P}$ dissolved pool. The organic, dissolved, and vegetation $P$ pools are very similar for the three types of input, although weathering was defined as a function of soil moisture (Eq. 1). We would therefore expect greater $P$ weathering in wet regions. However, for systems in steadystate, weathering becomes independent of soil moisture, as can be seen from the solution,

$\hat{F_{\mathrm{wd}}}=\hat{F_{\mathrm{wd}}}=k_{\mathrm{w}} f_{\mathrm{w}}(s) \hat{P_{\mathrm{w}}}=k_{\mathrm{w}} f_{\mathrm{w}}(s)\left(\frac{I_{\mathrm{w}}}{k_{\mathrm{w}} f_{\mathrm{w}}(s)}\right)=I_{\mathrm{w}}(24)$

This is due to dry regions having more material to be weathered, but less moisture, while humid places have less material to be weathered but more moisture. Moreover, due to water-related losses, we observe a generalized P-depletion in humid ecosystems (see Fig. 1 in Okin et al., 2004 for the estimated soil $\mathrm{P}$ concentration in the top $20 \mathrm{~cm}$ ). The concentration of $\mathrm{P}$ in the first $20 \mathrm{~cm}$ of the soil in dry regions tends to be higher than in wet regions (Cross and Schlesinger, 1995). Our model successfully represents this pattern.

Although there is an increasing concentration of $\mathrm{P}$ in soil organic matter with ecosystem dryness (Fig. 2), mineralization increases with soil moisture, leading to a peak in the mineralization rate at intermediate soil moisture. This results in the dissolved pool (Fig. 2d) having a maximum at about $s=0.55$. The biotic fluxes $\left(F_{\mathrm{dv}}, F_{\mathrm{vo}}\right.$ and $\left.F_{\mathrm{od}}\right)$ are larger than the inorganic fluxes, with the size of the dissolved pool determined mainly by mineralization.

\subsubsection{Sensitivity of organic biomass losses to soil moisture}

Natural ecosystems have less P losses from organic biomass, than agricultural systems (Brady and Weil, 2008). Processes such as fire, herbivory and intensive rain events drive losses of organic P from the system. Figure 3 shows the sensitivity of three forms of organic matter losses to soil moisture. $k_{\mathrm{r}}$ represents systems with organic losses mainly driven by water $O_{\mathrm{o}}=\left(0.5 k_{\mathrm{f}}+5 k_{\mathrm{r}} L Q(s)\right) P_{\mathrm{o}}$, which results in the accumulation of $\mathrm{P}$ in dry regions. However, in dry regions wind erosion plays an important role by removing soil and biomass (Artaxo and Hansson, 1994). Therefore, at the other extreme, $k_{\mathrm{f}}$ representing systems with organic matter losses mainly independent from water losses, using a constant rate $O_{\mathrm{o}}=\left(5 k_{\mathrm{f}}+0.5 k_{\mathrm{r}} L Q(s)\right) P_{\mathrm{o}}$. We observe in this case that $P_{\mathrm{v}}$ increases with soil moisture. A combination of the two, $O_{\mathrm{o}}=\left(k_{\mathrm{r}} L Q(s)+k_{\mathrm{f}}\right) P_{\mathrm{o}}$, gives values in the acceptable ranges of 5-15 $\mathrm{g} \mathrm{P} \mathrm{m}^{-2}$ for $P_{\mathrm{o}}$ and $20-50 \mathrm{~g} \mathrm{P} \mathrm{m}^{-2}$ for $P_{\mathrm{v}}$ (Brady and Weil, 2008). 

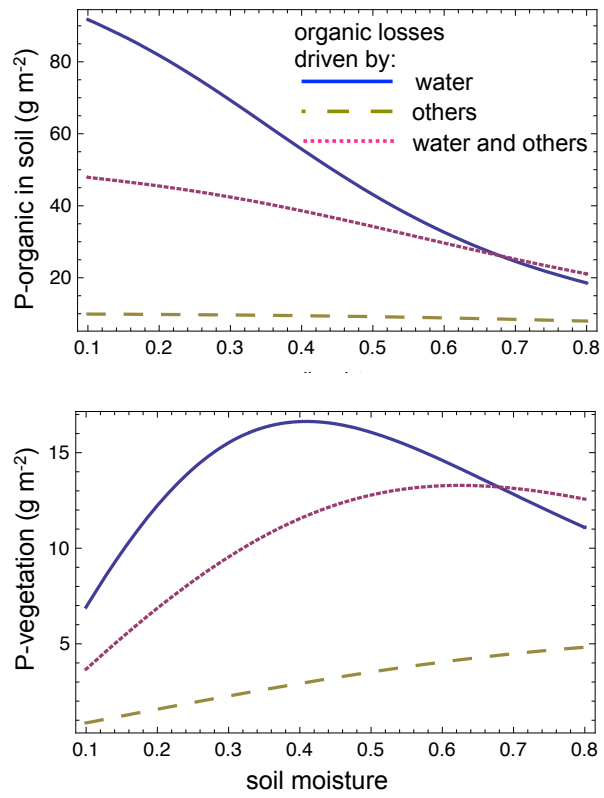

Fig. 3. Sensitivity of organic biomass losses to soil moisture. For ecosystems in steady-state, we compare the effect of soil moisture on three different schemes of $\mathrm{P}$ in organic biomass losses $\left(O_{\mathrm{O}}\right)$. The solid line represents ecosystems with organic matter losses that are mainly driven by water. The dashed line presents ecosystems with organic matter losses mainly driven by wind, human biomass removal and fires $\left(k_{\mathrm{f}}\right)$ and the dotted line represents ecosystems with losses by both, $k_{\mathrm{f}}$ and $k_{\mathrm{r}}$. The panel below illustrates the steady state for $\mathrm{P}$ in vegetation Eq. (22) and the panel above represents the $\mathrm{P}$ in soil organic biomass Eq. (21). For this simulation we used $I_{\mathrm{d}}=I_{\mathrm{W}}=0.0125 \mathrm{~g} \mathrm{P} \mathrm{m}^{-2} \mathrm{a}^{-1}$ and the values in Table 2 .

\subsubsection{Sensitivity of active $P$ uptake by vegetation to soil moisture}

Symbiosis between plants and mycorrhizae are very common, especially in ecosystems with low $P_{\mathrm{d}}$ concentrations (Cuevas and Medina, 1988; Vitousek and Sanford, 1986; Jordan and Herrera, 1981). Figure 4 illustrates the sensitivity of active $\mathrm{P}$ uptake to soil moisture. Ecosystems that do not invest in symbiotic relations will have more $\mathrm{P}$ occluded, and also more dissolved P. Increasing active uptake minimizes the losses of $\mathrm{P}$ in the system, leading to higher $\mathrm{P}$ concentrations in vegetation and in soil organic matter. This mechanism illustrates how particularly humid ecosystems, with low $\mathrm{P}$ input, can reduce $\mathrm{P}$ losses to clays and also to leaching. In the long term, this helps the ecosystem cope with low $\mathrm{P}$ inputs from the atmosphere and weathering.

\subsubsection{Special solutions for systems without uplift}

As previously mentioned, a system without uplift and exposed to erosion and weathering reaches a non-trivial steadystate only in the presence of exogenous inputs (Walker and
Syers, 1976). In this special case, the solution simplifies into

$\hat{P_{\mathrm{w}}}=0$

$\hat{M}_{\mathrm{m}}=0$

$\hat{P}_{\mathrm{c}}=0$

$\hat{P}_{\mathrm{o}}=\frac{k_{\mathrm{v}} \hat{P}_{\mathrm{v}}}{k_{\mathrm{d}} f(s, T)+k_{\mathrm{f}}+k_{\mathrm{r}} L Q(s)}$

$\hat{P}_{\mathrm{v}}=\frac{T(s) \hat{P}_{\mathrm{d}}}{k_{\mathrm{v}}}$

$\hat{P}_{\mathrm{d}}=$

$\frac{I_{\mathrm{d}} n Z_{\mathrm{r}} s\left(k_{\mathrm{d}} f(s, T)+k_{\mathrm{r}} L Q(s)\right)}{(L Q(s)+T(s))\left(k_{\mathrm{f}}+k_{\mathrm{r}} L Q(s)\right)+k_{\mathrm{d}} f(s, T) L Q(s)}$

When primary minerals are depleted, weathering and the formation of secondary minerals stops. At a later state, secondary mineral saturation and erosion decreases the $\mathrm{P}$ occluding capacity of the soils; only then can the system reach its steady-state. This results in an ecosystem dependent only on the effective recycling and the exogenous inputs, where soil processes no longer play an important role.

\subsection{Phosphorus temporal dynamics}

Since we cannot assume that all the terrestrial ecosystems reach their steady-state with respect to the $\mathrm{P}$ cycle, in the following we discuss how the system changes in time and how such changes are related to soil moisture and system inputs. In particular, we show how the transient solution of our model reproduces the dynamics of the classical conceptual model for the P cycle of Walker and Syers (1976) and the Franz Josef chronosequence. We then qualitatively compare our model results to the Hawaii chronosequence data (Crews et al., 1995; Chadwick et al., 1999). In the Crews et al. (1995) chronosequence of Hawaii, the soil development started shortly after the formation of the volcanic island, while in the chronosequence considered by Walker and Syers (1976) in New Zealand, the soil development starts shortly after the retreat of the Franz Josef glacier. Both systems feature negligible uplift while being subject to soil losses. To contrast this behavior, we consider the case of the Amazon Basin, where the situation is represented by slow constant uplift rates. The time dependent solutions are calculated using a standard numerical integration of the model (Eqs. 12-17).

These ecosystems all reach a state of $\mathrm{P}$ depletion, and it is likely that they have developed mechanisms to reduce the P losses in organic form (Jordan and Herrera, 1981; Cuevas and Medina, 1988), so that their values for $k_{\mathrm{r}}$ and $k_{\mathrm{f}}$ are particularly low. Such mechanisms include root mats and strong association with mycorrhizae, which favor active uptake of $\mathrm{P}$ (we set $k_{\mathrm{u}}$ to 10). As mentioned before, moreover, animals import of $\mathrm{P}$ from ocean and fresh water ecosystems may be relevant. The parameters used for the simulation are given in Table 2. 
Table 3. Parameter description for specific simulations.

\begin{tabular}{lllll}
\hline Parameter & Units & Franz Josef & Hawaii \\
\hline tectonic uplift rate & $\mathrm{mm}^{-1} \mathrm{a}^{-1}$ & 0 & 0 & Amazon Basin \\
P in rock & $\mathrm{mol} \mathrm{m}^{-3}$ & 38 (Porder et al., 2007) & 200 (Crews et al., 1995) \\
atmospheric input & $\mathrm{g} \mathrm{m}^{-2} \mathrm{a}^{-1}$ & 0.01 (Walker and Syers, 1976) & 0.008 (Kurtz et al., 2001) & 0.0057 (Kronberg et al., 1979) \\
animal input & $\mathrm{g} \mathrm{m}^{-2} \mathrm{a}^{-1}$ & 0 & 0.001 & $0.0011-0.0048$ (Swap et al., 1992) \\
$k_{\mathrm{W}}$ & $\mathrm{a}^{-1}$ & $0.00021 / 0.7$ estimated from (Walker and Syers, 1976) & $0.000015 / 5$ estimated from Chadwick et al. (1999) & 0.0001 \\
$k_{\mathrm{m}}$ & $\mathrm{a}^{-1}$ & 1.0 & 0.5 & 0.7 \\
$T$ & ${ }^{\circ} \mathrm{C}$ & 11 & 16 & 0.4 \\
$s$ & & 0.7 & 0.4 & 0.6 \\
\hline
\end{tabular}
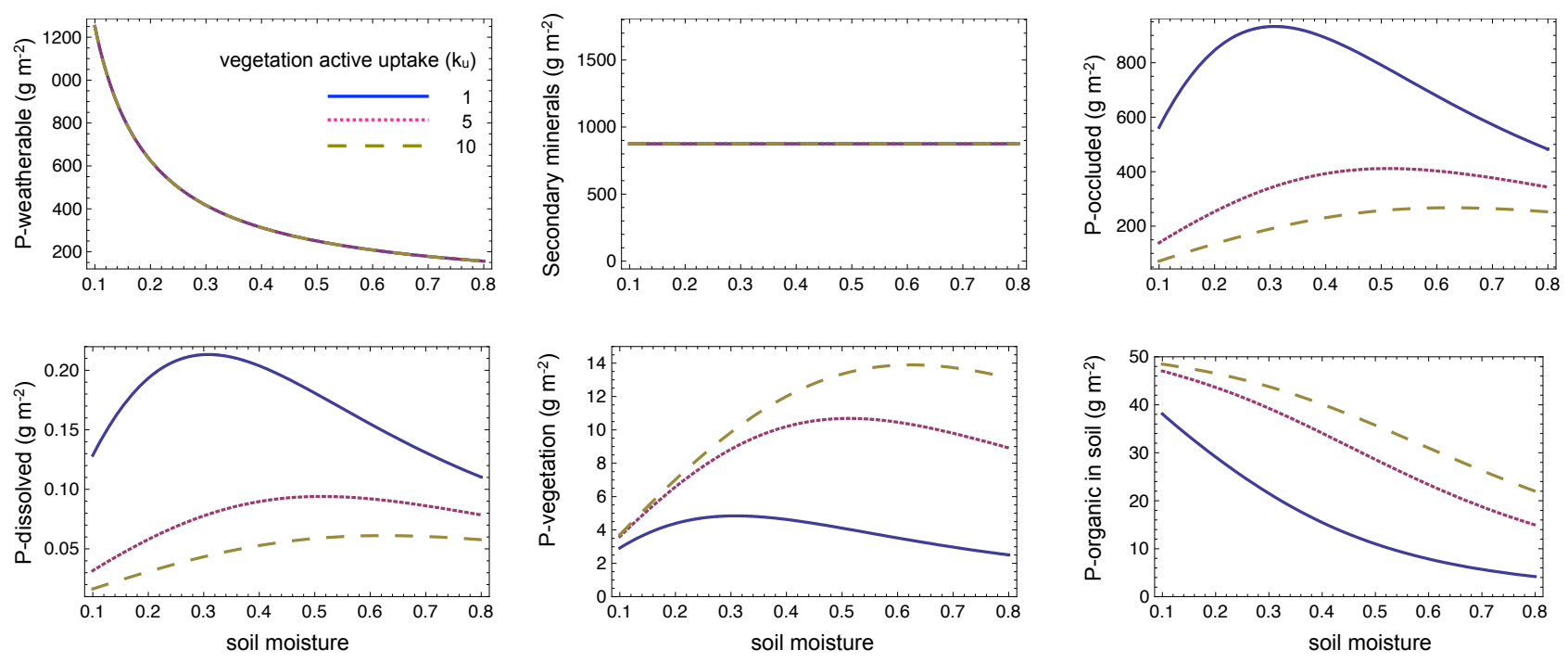

Fig. 4. Active $\mathrm{P}$ vegetation uptake $\left(k_{\mathrm{u}}\right)$ sensitivity to soil moisture. To compare the result of the symbiotic relationship within ecosystems we simulated ecosystems with different uptake rates: the dashed lines represent no symbiosis $\left(k_{\mathrm{u}}=1\right)$, the solid lines represent strong symbiosis $\left(k_{\mathrm{u}}=10\right)$, and the dotted lines represent intermediate symbiosis $\left(k_{\mathrm{u}}=5\right)$. For these simulations, we used the steady-state solution $($ Eqs. 18-23). For the parameters used refer to Table 2 and to the system input parameters for the Amazon Basin in Table 3.

\subsubsection{The Walker and Syers' model for New Zealand}

The Franz Josef glacial area is located on the west side of New Zealand's Southern Island, which was formed during the collision of the Pacific and Australia continental plates during the late Cenozoic (Tippett and Kamp, 2003). Glaciers removed the first soil layer, leaving glacial till behind upon retreat. After the glacial retreats, soil formation re-started, now based on this deposited parent material with very low $\mathrm{P}$ concentration and already physically weathered. If one only considers the soil after the glacial retreat, further uplift input may be assumed negligible (the main parameters for this systems are reported in Table 3). Walker and Syers (1976) developed a conceptual scheme for phosphorus during pedogenesis, based on data from the Franz Josef glacial retreat chronosequence.

We assume a mean annual atmospheric input of $0.01 \mathrm{~g} \mathrm{P} \mathrm{m}^{-2}$ (without considering animal $\mathrm{P}$ inputs) and an initial pool of primary mineral $\mathrm{P}$ of $38 \mathrm{~mol} \mathrm{P} \mathrm{m}^{-2}$ (Porder et al., 2007) only $70 \mathrm{~cm}$ in depth. We also assume that only $50 \%$ of the initial primary material pool can be weathered, to account for the fact that a good proportion of the primary material may be non-weatherable and/or lost from the system due to subsidence, erosion and lateral processes. With these data, the temporal dynamics of our model reproduces well the behavior of Walker and Syers' conceptual model and data for Franz Josef (Walker and Syers, 1976). In Fig. 5 we see how $\mathrm{P}$, once released from its geologic source, is converted into less available (P-occluded) forms or is lost from the terrestrial system. With no more inputs of primary mineral the steady-state depends only on exogenous input. The $P_{\mathrm{v}}, P_{\mathrm{o}}$, and $P_{\mathrm{d}}$ pools apparently reach their steady-states short after the depletion of the parent material at about $22000 \mathrm{a}$. This coincides with what Walker and Syers (1976) called the "terminal steady-state". However, the truly steady-state for this system (Eqs. 25-30) occurs only when the secondary minerals no longer account for further looses to the system, at 

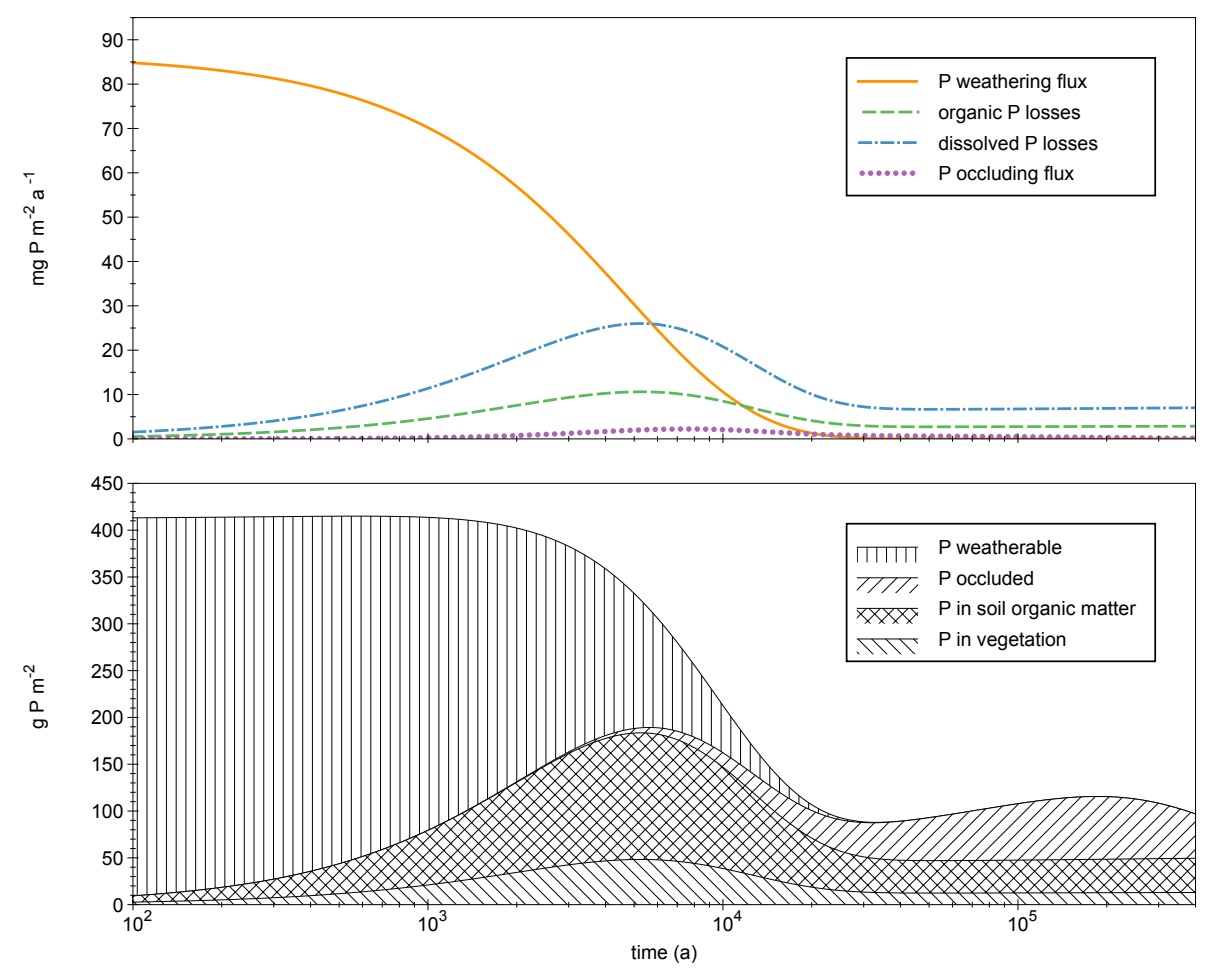

Fig. 5. Modeled phosphorus dynamics for the Franz Josef chronosequence. This simulation uses the climate and atmospheric input for the Franz Josef, found in Tables 2 and 3. The upper figure shows the evolution of the fluxes as the soil is formed, and the lower figure shows the evolution of the P pools. The evolution of the soil pools is comparable to Walker and Syers (1976) Franz Josef chronosequence data. Note that the $\mathrm{x}$-axis is plotted on a logarithmic scale.

about five hundred thousand years. Although occlusion rate is minimal during the whole simulation (Fig. 5, upper panel), the P-occluded pool is maximum at about 200000 a (Fig. 5, lower panel). It should be noticed that, for this chronosequence, the external losses are more important than occlusion. Despite the low P concentration in the rock, at the beginning of this chronosequence weathering rates are really high mainly due to three factors: very high precipitation rates, annual variation in temperature which increases physical weathering and the fact that the initial material is of depositional origin, and thus already physically weathered (Fig. 5, above panel). This, as we will see, contrasts with volcanic soils.

\subsubsection{The Hawaii chronosequence}

The Hawaiian archipelago is part of the Hawaiian-Emperor Ocean Mountain Range formed by hotspot volcanism moving in a southeast direction (Steinberger et al., 2004). This movement creates an island-age-gradient, which provides a perfect scenario to define a chronosequence. Hotspot volcanism forms the islands in a progressive way, while climate acts by weathering the fresh exposed rock and together with the topographical gradient, acts to enhance soil erosion.
To model the $\mathrm{P}$ dynamics of these islands, we consider the start of the model simulation shortly after the formation of the island. The initial $P_{\mathrm{w}}$ pool represents the total amount of $P$ in fresh rock material left by the volcanic activity. For the simulation, we assume $5 \mathrm{~m}$ of rock material to account for the large pool of primary mineral left after the formation of the island. For this chronosequence we used a very slow weathering parameter $k_{\mathrm{w}}=0.000015 / 5$ which accounts for the fact that most of the volcanic material (except for ashes) needs first to be physically weathered and that in the tropics the annual temperature variation is minimal resulting in slow physical weathering. As the hotspot moves, there is no more uplift of material, and therefore we run the simulation with no uplift (i.e., $I_{\mathrm{w}}=0$ ). Hawaii receives very low $\mathrm{P}$ atmospheric input (Kurtz et al., 2001). Refer to Tables 2 and 3 for the parameters used for the simulation.

Our simulations shows a general agreement with Crews et al. (1995) data. Both systems start with a large pool of $P_{\mathrm{w}}$, although our initial pool is much larger, as we consider all the weatherable $\mathrm{P}$ in $5 \mathrm{~m}$ of basaltic rock and not only the top $50 \mathrm{~cm}$. Productivity peaks at ca. $100000 \mathrm{a}$ and at ca. $1 \mathrm{Ma}$ as the $P_{\mathrm{w}}$ is depleted, after which the ecosystem depends only on $I_{\mathrm{d}}$. As the soil evolves the external P losses decrease. However, another consequence of soil development is the formation of $M_{\mathrm{m}}$, increasing occlusion capacity, which 

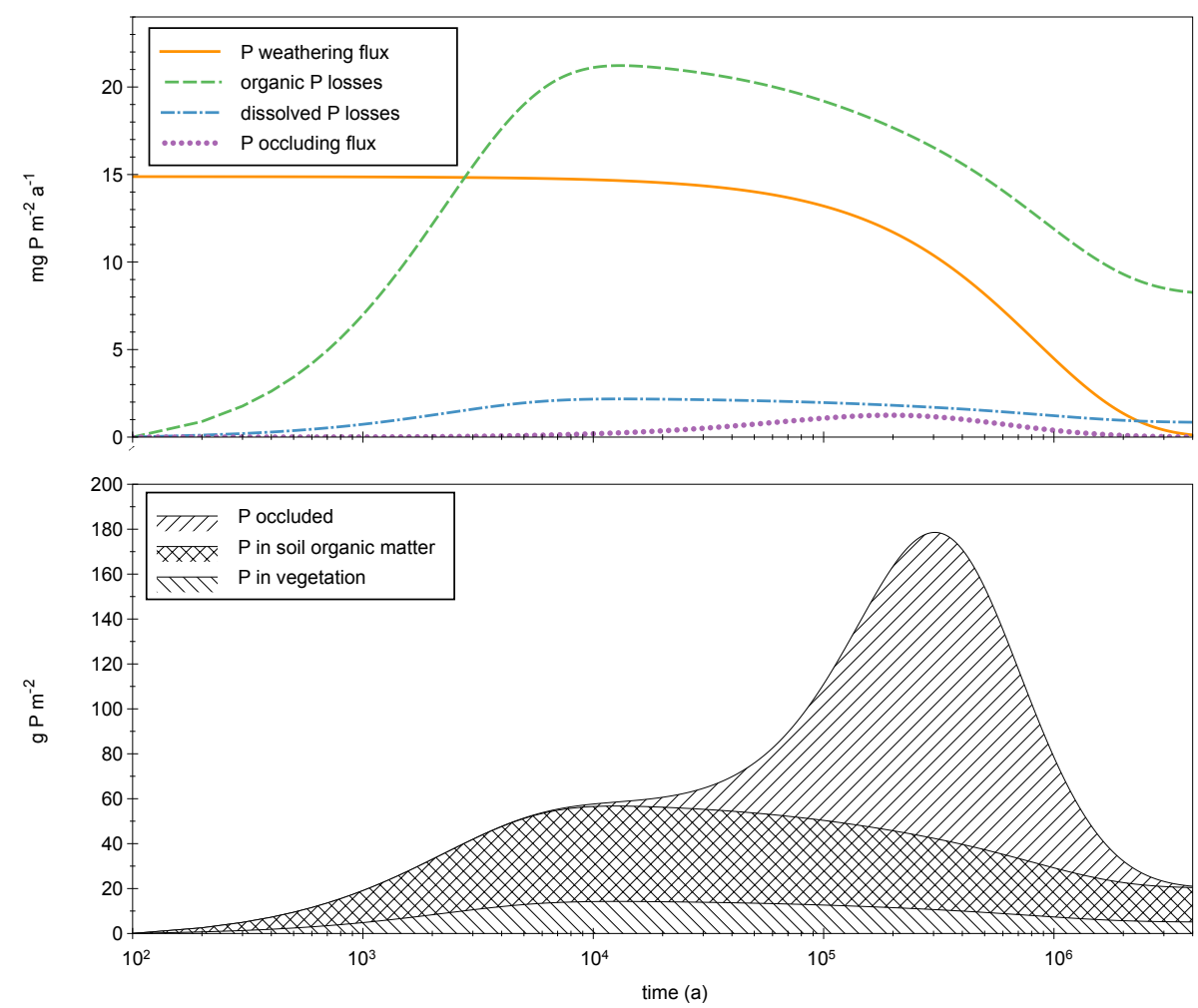

Fig. 6. $\mathrm{P}$ temporal dynamics for an ecosystem with a large initial amount of primary minerals. Simulated phosphorus transformation in time are shown using the parameters for Hawaii given in Tables 2 and 3. The upper figure shows how the fluxes change during soil evolution. The lower figure represents the pools. For this transient solution we do not represent the $\mathrm{P}$ weatherable pool as it is not comparable with Crews et al. (1995) who only measured the first $50 \mathrm{~cm}$, while our simulation started with $5 \mathrm{~m}$ of parent material. However, weathering is comparable to Chadwick et al. (1999) weathering rates for Hawaii, which starts at about $20 \mathrm{mg} \mathrm{P} \mathrm{m}^{2} \mathrm{a}^{-1}$ at about $2000 \mathrm{a}$ and goes to $0,1 \mathrm{mg} \mathrm{P} \mathrm{m} \mathrm{a}^{-1}$ at about $4 \mathrm{Ma}$. Note that the $\mathrm{x}$-axis is plotted on a logarithmic scale.

results in a peak of $P_{\mathrm{c}}$ almost coinciding with the end of the $P_{\mathrm{w}}$ pool.

It should be noted that the decay in the P-organic pool may be delayed by $\mathrm{P}$ de-occlusion (ecosystems can invest carbon to de-occlude P) at the expense of the P-occluded pool. This fact may also act as a P-storage mechanism, which delays the approach to steady state. However, in the long run, lateral erosion provides $P_{\mathrm{c}}$ and $M_{\mathrm{m}}$ losses which ultimately lead to a steady-state of the system after more than $4 \mathrm{Ma}$.

\subsubsection{Dynamics of an uplift dominated site (the Amazon Basin)}

In contrast with the $\mathrm{P}$ dynamics for the subducting part of two colliding plates (Franz Josef chronosequence) and the hotspot volcanism in the ocean crust forming the EmperorHawaiian Mountain Range (Hawaii chronosequence), continental crust dynamics differ due to the lower material crust densities which allow the crust to float on the magma. To represent ecosystem dynamics on continental crust in a system that is relatively stable, we assume constant uplift rates. Figure 7 presents the dynamics of an ecosystem with very slow uplift rates, high soil moisture, and low atmospheric inputs similar to the ones reported for the Amazon Basin. To account for the dynamics on the continental crust, an intermediate value for $k_{\mathrm{w}}$, in between the ones estimated for Hawaii and Franz Josef, was chosen. In the Amazon, animal inputs come from the extensive river system, which carries nutrients mainly coming from the Andes; some of the input however also comes from low-land basins. The parameters used for the simulation are reported in Tables 2 and 3.

The system slowly reaches a steady-state in which the soil processes still play an important role and the P-occluded is large compared to the P-organic. The system quickly recycles the organic matter, due to high temperatures and soil moisture conditions, leading to large fluxes between the soil and the vegetation. This behavior contrasts to the observational data and modeled results for Hawaii and for Franz Josef. Stable continental crust reaches a steady-state in which the soils are constantly regenerated due to the erosionuplift balance. Therefore, even in steady-state, secondary minerals $\left(M_{\mathrm{m}}\right)$ represent a $\mathrm{P}$ sink to the system, as they continue occluding P (see Fig. 7), while the are also constantly formed and eroded away. However, the external losses of $P_{\mathrm{o}}$ 

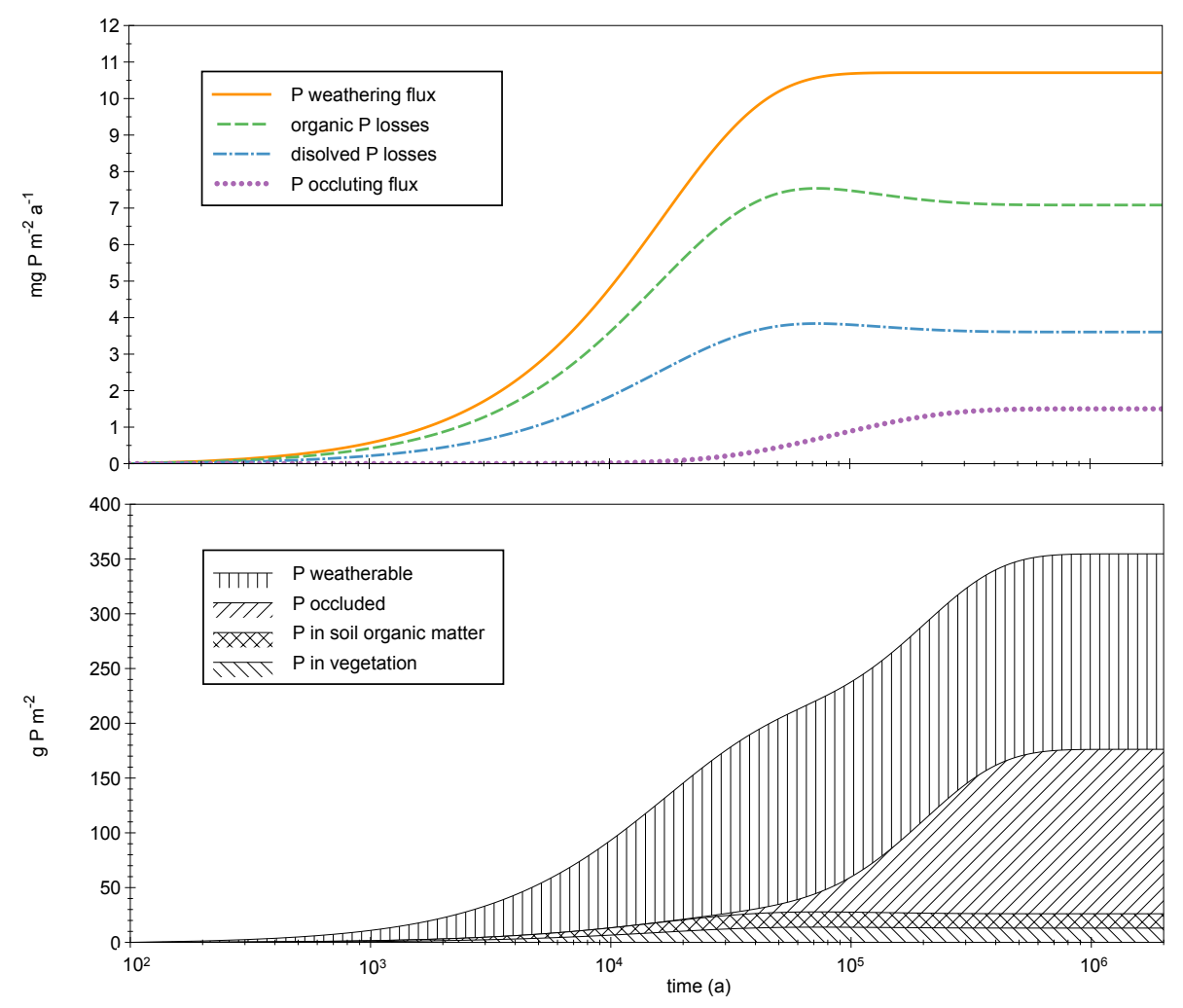

Fig. 7. Modelled $\mathrm{P}$ dynamics for an ecosystem with slow uplift rates. This simulation uses the climate and atmospheric input for the Amazon Basin, found in Tables 2 and 3. The upper figure shows the evolution of the fluxes as the soil is formed, and the lower figure shows the evolution of the $\mathrm{P}$ pools. Note that the $\mathrm{x}$-axis is plotted on a logarithmic scale.

and $P_{\mathrm{d}}$ are also larger in this system. The slow uplift rates results in a system in which the two inputs $I_{\mathrm{w}}$ and $I_{\mathrm{d}}$ play an important role.

\section{Summary and conclusions}

In this article we examined the effects of tectonic processes and exogenous inputs on the P-cycle. We have shown how steady states of productivity depend on exogenous inputs for systems that do not feature uplift such as terrestrial ecosystems on oceanic crust or systems experiencing subduction. We have also shown how the steady-state is not immediately reached after the primary mineral is depleted, but instead after the occluding minerals are stabilized (not accounting for further losses of P). We contrasted this to ecosystems on continental stable crust, where $\mathrm{P}$ occlusion and weathering play important roles in the transient, as well as, in the steady-state productivity of the ecosystems.

Hydroclimatic conditions, which are assumed to be constant, determine how fast ecosystems reach their steady-state (Walker and Syers, 1976), with humid ecosystems reaching this steady-state faster. This was well reproduced by our model, which also showed that steady-state wet ecosystems generally run on a lower $\mathrm{P}$ budget because the $\mathrm{P}$ losses increase with soil moisture, while the inputs remain constant.
This suggests that humid climates are not only P depleted because they reach their steady state faster, as proposed by Walker and Syers (1976), but also because they have a lower $\mathrm{P}$ budget, due to larger steady-state losses. Finally, in the case of low atmospheric and tectonic P inputs, ecosystems may rely on mechanisms to overcome $\mathrm{P}$ losses, such as the reduction of organic losses, increased $\mathrm{P}$ inputs from animals and vegetation symbiotic relations with mycorrhizae.

In summary, our simple dynamical system helps answer some of the complicated questions related to the origins and conditions of P limitation and how ecosystems may influence the $\mathrm{P}$ cycle in order to maintain $\mathrm{P}$ available for further growth. Moreover, we believe that the model simplicity and applicability to regional and global dynamics may also facilitate its coupling to other models of biogeochemical processes.

This model reproduces observations relatively well indicating that the important processes describing the terrestrial $\mathrm{P}$ dynamics are captured. The next step will be to implement this model into a global vegetation model, allowing it to represent climatic and tectonic forcing more explicitly. This will then allow us to quantify the importance of the $\mathrm{P}$ dynamics for terrestrial productivity, as well as the implications of $\mathrm{P}$ limitation for the response of terrestrial ecosystems to the different aspects of global change. 
Acknowledgements. C. B. would like to thank the Biospheric theory and modeling group, Primǎvara Grigoriu and Álvaro Buendía for the stimulating discussion and comments. A. P. acknowledges the US National Science Foundation under grants EAR-0628432 and EAR-0635787, a collaboration grant from the US Department of Agriculture 58-6206-7-029, Agricultural Research Service, Temple, TX and the support of the Landolt and Cie Chair "Innovative strategies for a sustainable future" at the École Polytechnique Fédérale de Lausanne, Switzerland. We also thank G. Esser, S. Manzoni and two anonymous reviewers for their useful comments.

The service charges for this open access publication have been covered by the Max Planck Society.

Edited by: U. Seibt

\section{References}

Artaxo, P. and Hansson, H.: Size distribution of biogenic aerosol particles from the Amazon Basin, Atmos. Environ., 29, 393-402, 1994.

Brady, N. C. and Weil, R. R.: The Nature and Properties of Soil, Prentice Hall, 13. edition, 2008.

Chadwick, O. A., Derry, L. A., Vitousek, P. M., Huebert, B. J., and Hedin, L.: Changing sources of nutrients during four million years of ecosystem development, Nature, 397, 491-497, 1999.

Chameides, W. L. and Perdue, E. M.: Biogeochemical Cycles: A Computer-Interactive Study of Earth System Science and Global Change, Oxford University Press, 1997.

Cramer, W., Bondeau, A., Woodward, F., Prentice, I., Betts, R., Brovkin, V., Cox, P., Fisher, V., Foley, J., Friend, A., Kucharik, C., Lomas, M., Ramankutty, N., Sitch, S., Smith, B., White, A., and Young-Molling, C.: Global response of terrestrial ecosystem structure and function to $\mathrm{CO}_{2}$ and climate change: results from six dynamic global vegetation models, Global Change Biol., 7, 357-373, 2001.

Crews, T., Kitayama, K., Fownes, J., and Riley, R.: Changes in soil phosphorus fractions and ecosystem dynamics across a long chronosequence in Hawaii, Ecology, 75, 1407-1424, 1995.

Cross, A. F. and Schlesinger, W. H.: A literature review and evaluation of the Hedley fractionation: Applications to the biogeochemical cycles of soil phosphorus in natural ecosystems, Geoderma, 64, 197-214, 1995.

Cuevas, E. and Medina, E.: Nutrient Dynamics within Amazonian Forests, II. Fine Root Growth, Nutrient Availability and Leaf Litter Decomposition, Oecologia, 76, 222-235, 1988.

DeLonge, M. P., D’Odorico, P., and Lawrence, D.: Feedbacks between phosphorous deposition and canopy cover: the emergence of multiple states in dry tropical forests, Global Change Biol., 14, 154-160, doi:10.1111/j.1365-2486.2007.01470.x, 2008.

Herrera, R., Jordan, C. F., Medina, E., and Klinge, H.: How Human Activities Disturb the Nutrient Cycles of a Tropical Rainforest in Amazonia, Ambio, 10, 109-114, 1981.

Hungate, B. A., Dukes, J. S., Shaw, M. R., Luo, Y., and Field, C. B.: Nitrogen and Climate Change, Science, 302, 1512-1513, 2003.

Jordan, C. F.: The nutrient balance of an amazonian rain forest, Ecology, 61, 14-18, 1982.
Jordan, C. F. and Herrera, R.: Tropical rain forests: are nutrients really critical?, Am. Nat., 117, 167-180, 1981.

Katul, G., Porporato, A., and Oren, R.: Stochastic dynamics of plant?water interactions, Annu. Rev. Ecol. Evol. S., 38, 767-791, 2007.

Kronberg, B., Fyfe, W., Leonardos, O., and Santos, A.: The chemistry of some Brazilian soils: Element mobility during intense weathering, Chem. Geol., 24, 211-229, 1979.

Kurtz, A. C., Derry, L. A., and Chadwick, O. A.: Accretion of Asian dust to Hawaiian soils: Isotopic, elemental, and mineral mass balances, Geochim. Cosmochim. Ac., 65, 1971-1983, 2001.

Lasaga, A.: The kinetic treatment of geochemical cycles, Geochim. Cosmochim. Ac., 44, 815-828, 1980.

Lawrence, D., D’Odorico, P., Diekmann, L., DeLonge, M., Das, R., and Eaton, J.: Ecological feedbacks following deforestation create the potential for a catastrophic ecosystem shift in tropical dry forest, P. Natl. Acad. Sci., 104, 20696-20701, 2007.

Mahowald, N. M., Artaxo, P., Baker, A. R., Jickells, T. D., Okin, G. S., Randerson, J. T., and Townsend, A. R.: Impacts of biomass burning emissions and land use change on Amazonian atmospheric phosphorus cycling and deposition, Global Biogeochem. Cy., 19, GB4030, doi:10.1029/2005GB002541, 2005.

Manzoni, S., Porporato, A., D’Odorico, P., Laio, F., and RodriguezIturbe, I.: Soil nutrient cycles as a nonlinear dynamical system, Nonlinear Proc. Geoph., 11, 589-598, 2004.

Manzoni, S., Trofymow, J. A., Jackson, R. B., and Porporato, A.: Stoichiometric controls on carbon, nitrogen, and phosphorus dynamics in decomposing litter, Ecol. Monogr., 80, 89-106, 2010.

McGroddy, M., Daufresne, T., and Hedin, L.: Scaling of C:N:P stoichiometry in forests worldwide: Implications of terrestrial redfield-type ratios, Ecology, 85, 2390-2401, 2004.

Newman, E.: Phosphorus inputs to terrestrial ecosystems, J. Ecol., 83, 713-726, 1995.

Okin, G. S., Mahowald, N., Chadwick, O. A., and Artaxo, P.: Impact of desert dust on the biogeochemistry of phosphorus in terrestrial ecosystems, Global Biogeochem. Cy., 18, GB2005, doi: 10.1029/2005GB002541, 2004.

Olander, L. and Vitousek, P.: Short-term controls over inorganic phosphorus during soil and ecosystem development, Soil Biol. Biochem., 37, 651-659, doi:10.1016/j.soilbio.2004.08.022, 2005.

Parton, W., Stewart, J., and Cole, C.: Dynamics of C, N, P and S in grassland soils: a model, Biogeochemistry, 5, 109-131, 1988.

Porder, S. and Chadwick, O. A.: Climate and soil-age constrains on nutrient uplift and retention by plants, Ecological Society of America, 90, 2009.

Porder, S., Vitousek, P. M., Chadwick, O. A., Chamberlain, C. P., and Hilley, G. E.: Uplift, Erosion and Phosphorus limitation in Terrestrial Ecosystems, Ecosystems, 10, 158-170, 2007.

Porporato, A., D’Odorico, P., Laio, F., and Rodriguez-Iturbe, I.: Hydrologic controls on soil carbon and nitrogen cycles, I. Modeling scheme, Adv. Water Resour., 26, 45-58, 2003.

Porporato, A., Daly, E., and Rodriguez-Iturbe, I.: Soil water balance and ecosystem response to climate change, Am. Nat., 164, 625632, 2004.

Richter, D. D., Allen, H. L., Li, J., Markewitz, D., and Raikes, J.: Bioavailability of slowly cycling soil phosphorus: major restructuring of soil $\mathrm{P}$ fractions over four decades in an aggrading forest, Oecologia, 150, 259-271, doi:10.1007/s00442-006-0510, 2006. 
Rodriguez-Iturbe, I. and Porporato, A.: Ecohydrology of watercontrolled ecosystems: soil moisture and plant dynamics, Cambridge Univ. Press, 2004.

Rosenzweig, M. L.: Net Primary Productivity of Terrestrial Communities: Prediction from Climatological Data, Am. Nat., 102, 67-74, 1968.

Sanchez, P. A., Villachica, D. E. B. J. H., and Nicholaides, J. J.: Amazon Basin soils: Management for continuous crop production, Science, 216, 99-114, 1982.

Steinberger, B., Sutherland, R., and O'Connell, R. J.: Prediction of Emperor-Hawaii seamount locations from a revised model of global plate motion and mantle flow, Nature, 430, 167-173, 2004.

Stevens, P. R. and Walker, T. W.: Chronosequence concept and soil formation, Q. Rev. Biol., 45, 333-350, 1970.

Strogatz, S. H.: Nonlinear Dynamics and Chaos: With Applications to physics, Biology, Chemistry, and Engineering, Cambridge, MA, Perseus Books, 1994.

Swap, R., Garstang, M., and Greco, S.: Saharan dust in the Amazon Basin, Tellus B, 44, 133-149, 1992.

Tippett, J. and Kamp, P. J. J.: The role of faulting in rock uplift in the Southern Alps, New Zealand, New Zeal. J. Geol. Geop., 36, 497-504, 2003.
Vitousek, P. M. and Sanford, R. L.: Nutrient Cycling in Moist Tropical Forest, Annu. Rev. Ecol. Syst., 17, 137-167, 1986.

Walker, T. W. and Syers, J. K.: The fate of phosphorous during pedogenesis, Geoderma, 15, 1-19, 1976.

Wang, Y. P., Houlton, B., and Field, C. B.: A model of biogeochemical cycles of carbon, nitrogen and phosphorus including symbiotic nitrogen fixation and phosphatase production, Global Biogeochem. Cy., 21, GB1018, doi:10.1029/2006GB002797, 2007.

Wardle, D. A.: Ecosystem Properties and Forest Decline in Contrasting Long-Term Chronosequences, Science, 305, 509-513, doi:10.1126, 2004.

Wardle, D. A., Bellingham, P. J., Bonner, K. I., and Mulder, C. P. H.: Indirect effects of invasive predators on litter decomposition and nutrient resorption on seabird-dominated islands, Ecology, 90, 452-464, 2009.

Wood, T., Bormann, F. H., and Voigt, G. K.: Phosphorus cycling in a northern hardwood forest: Biological and chemical control, Science, 223, 391-393, 1984.

Zaehle, S., Friend, A. D., Friedlingstein, P., Dentener, F., Peylin, P., and Schulz, M.: Carbon and nitrogen cycle dynamics in the $\mathrm{O}-\mathrm{CN}$ land surface model, II: The role of the nitrogen cycle in the historical terrestrial C balance, Global Biogeochem. Cy., 24, 14 pp., doi:10.1029/2009GB003522, 2010. 